\title{
Teaching Linear Programing in Mathematics Education to Improve Human Health
}

\author{
Beatrice Nakhanu Shikuku ${ }^{1^{*}}$ \\ ${ }^{1}$ Masinde Muliro University of Science and Technology, Kenya.
}

Author's contribution

The sole author designed, analyzed and interpreted and prepared the manuscript.

Article Information

DOI: $10.9734 / J S R R / 2017 / 33181$

Editor(s):

(1) Chun-Gang Zhu, School of Mathematical Sciences, Dalian University of Technology, China.

Reviewers:

(1) Demeke Fisseha, Indian Institute of Technology Roorkee, Roorkee, India.

(2) Isack E. Kibona, College of Mathematics and Statistics, Central China Normal University, China.

(3) Nityanand Pai, Manipal University, India.

Complete Peer review History: http://www.sciencedomain.org/review-history/19041

Review Article

Received $1^{\text {st }}$ April 2017

Accepted $9^{\text {th }}$ May 2017

Published 12 ${ }^{\text {th }}$ May 2017

\begin{abstract}
The 1984 World Health Organization (WHO) defines health as "the extent to which an individual or group is able to realize aspirations and satisfy needs, and to change or cope with the environment." Health is a resource for everyday life. It is a positive concept emphasizing social and personal resources, as well as physical capacities. To maintain human health is a complex matter, thus the need to apply mathematics education, and in particular, linear programming knowledge and skills, in order to bring up a healthy community. Linear Programming is about making maximum benefit or minimum loss out of limited resources in daily life. Applications of linear programming date back to 1930 and were first attempted by the Soviet mathematician Leonid Kantorovich and by the American economist, Wasilly Leontief. Linear programming is applied in many health programs. These include; application of linear programming in health care, in the most affordable heath diet, in surgery, menu planning, food production and in feeding. Linear programming is used by farmers to determine how much space to be used for each crop especially when practicing mixed farming and for optimal health care resource allocation. Linear programming is also used in home health care and medical services. It is used in radiation therapy treatment, for menu planning in restaurants and in nurses scheduling. It is therefore recommended that the topic linear programming be taught to all Kenyan students irrespective of what career they hope to pursue. This will go a long way in enabling the Kenyan society to maintain good health at minimum cost.
\end{abstract}


Keywords: Mathematics education; linear programming; human health.

\section{INTRODUCTION}

This paper looks at the application of linear programming to improve human health. It is also to encourage mathematics educators to ensure that all topics in mathematics, especially linear programming are taught to all learners in Kenya and beyond. This is because linear programming is applied not just in the improvement of human health, but also in daily life activities. Mathematics on the other hand, plays a vital role in personal, national and global development. Its fundamental role lies in its application in most social sciences like geography, government and business transactions and in house hold chores. In addition, mathematics has been applied within various studies such as engineering, biology, medicine, economics, and in military advancement [1]. The secondary school mathematics curriculum in Kenya, covers a wide range of topics including: Numbers, Measurement, Algebra, Geometry, Trigonometry, Statistics, Probability, Matrices, Three dimension geometry and Linear programming. One topic that appears at both primary and secondary school level of learning mathematics in Kenya, is linear programming [2]. This is about making maximum benefits and minimum loss out of limited resources in daily life. Linear programming is an analytic method that can be used to develop models for health care that optimize distribution of resources through mathematical means. It is a decision model that was developed early in the history of operations research and has wide applicability [3].

Mathematics education, and Linear programming in particular is therefore applied in many health programs. These include; application of linear programming in health care [4], in the most affordable heath diet, in surgery [3], menu planning, food production and in feeding [5]. Linear programming is used by farmers to determine how much space to be used for each crop especially when practicing mixed farming and for optimal health care resource allocation [6]. Linear programming is also used in home health care and medical services. It is used in radiation therapy treatment, for menu planning in restaurants and in nurses scheduling [7].

On the other hand, From Wikipedia, the free encyclopaedia; Health is the level of functional and metabolic efficiency of a living organism. In humans it is the ability of individuals or communities to adapt and self-manage when facing physical, mental or social changes. The World Health Organization (WHO) defined health in its broader sense in its 1948 constitution as "a state of complete physical, mental, and social well-being and not merely the absence of disease or infirmity. This definition has been subject to controversy, in particular as lacking operational value, the ambiguity in developing cohesive health strategies, and because of the problem created by use of the word "complete". Other definitions have therefore been proposed, among them are recent definitions that correlate health and personal satisfaction. An example of such a definition of health is: "a state characterized by anatomic, physiologic, and psychological integrity; ability to perform personally valued family, work, and community roles; ability to deal with physical, biologic, psychological, and social stress". The 1984 WHO revised definition of health defined it as "the extent to which an individual or group is able to realize aspirations and satisfy needs, and to change or cope with the environment.

Thus, health is referred to, as the ability to maintain homeostasis and recover from insults. Mental, intellectual, emotional, and social health is referred to as a person's ability to handle stress, to acquire skills, to maintain relationships, all of which form resources for resiliency and independent living. The maintenance and promotion of health is achieved through different combination of physical, mental, and social wellbeing, together sometimes referred to as the "health triangle." The WHO's 1986 Ottawa Charter for Health Promotion further stated that health is not just a state, but also "a resource for everyday life, not the objective of living. Health is a positive concept emphasizing social and personal resources, as well as physical capacities." To maintain human health therefore is a complex matter, thus the need to apply linear programming knowledge and skills, in order to bring up a healthy community.

\subsection{The Problem}

From the foregoing information, linear programming is an important tool, whose application is key in daily life activities. However, Shikuku found that $94 \%$ of schools in Kakamega South District in Kakamega County (Kenya), did not teach this topic [8]. Also, the few students who were taught this topic went into careers like 
medicine and engineering with hardly any joining the human resource or nursing as a career. Some people who work in hotels either to serve or cook the food, have no knowledge of linear programing concept, yet they are expected to come up with a balanced diet, and also maximize on profits as they minimize on costs. Furthermore, from the many questions asked on the 'math forum @ Drexel' on linear programming, it is clear that many people both in and outside Kenya, do not understand the concept nor the application of linear programming skills. Thus the need to encourage mathematics educators to teach linear programming to learners at both primary and secondary school levels.

\section{RESEARCH DESIGN}

This is a desk top library research, where journals, internet, newspapers, books, and reports were consulted and studied. Secondary analysis allows maximum examination of existing data and can produce new and more detailed information, including the emergence of conclusions that differ from the original report [9]. It has high quality data and an additional strength is that, it is quick with easy access to materials as documentary research is largely free of the restrictions [10]. Secondary analysis avoids difficulties faced in primary data research, since researchers do not encounter rejection, non-response, bias, or any other respondent based problems [11].

\section{LITERATURE REVIEW}

This section looks at application of linear programming in various fields involving human health. These include; treatment of human beings, managing human beings and managing of resources while ensuring maximum benefits at minimum costs.

\subsection{Linear Programming to Optimize Performance in a Department of Surgery}

Linear programming is an analytic method that can be used to develop models for health care that optimize distribution of resources through mathematical means. In 2005, [3] it was found that by using a linear programming model in the department of surgery, the optimal solution produced an increase in professional payments and an increase in the hospital total margin. This solution favoured surgical procedures that require inpatient care since these patients had greater comorbidity, reflected in a higher casemix index. Also substantial differences were noted in the use of general care, number of days in ICU, and in consumption of preoperative, intraoperative, and recovery room time. It is therefore recommended that other departments should use similar linear programming models, to maximize the hospital margin. Also, other hospitals are encouraged to use linear programming models in as many departments as possible.

\subsection{Application of Linear Programming to Improve Management and Health Care}

Lyles observes that, in health care, linear programming is applied both to management decision making, and to decisions regarding clinical care [4]. Some examples in health where linear programming is applied include; linear programming used to improve breast cancer diagnosis. This is done on the basis of cell characteristics, from a fine needle biopsy and to model the likelihood of recurrence in surgically treated patients. Linear programming is also used to develop a model of costs and revenues, based on patient diagnostic groups for strategic planning at a major university medical centre. Further, linear programming is used to identify underutilized resources and inefficient production of services at the department of Veterans Affairs medical centre. Also, Parlesak [12] looked at Food-Based Dietary Guidelines developed to promote healthier eating patterns, without increasing food prices so as to make healthy eating affordable. The aim of the study was to design a range of cost-minimized nutritionally adequate health-promoting food baskets that help prevent both micronutrient inadequacy and diet-related non-communicable diseases at lowest cost. Average prices for 312 foods were collected within the Greater Copenhagen area. The cost and nutrient content of five different cost-minimized Food Baskets for a family of four were calculated per day using linear programming. The Food Baskets were defined using five different constraints namely: cultural acceptability, dietary guidelines, nutrient recommendations, both acceptability and nutrient recommendations and finally, both dietary guidelines and nutrient recommendations. With adjustments using linear programming, the best food baskets were identified. It was therefore concluded that; use of linear programming 
facilitates the generation of low-cost food baskets that are nutritionally adequate, health promoting, and culturally acceptable. This means that, linear programming is not just key in treatment of patients, but also in managing resources and costs.

In 2009, Collussi [13], looked at the application of Linear Programming to evaluate performance of Oral Heath in Primary Care. The study used data from 19 municipalities of Santa Catharina city, each with more than 50,000 habitants. It was observed that, municipalities that applied Linear Programming technique performed better than their counterparts, in terms of maximizing on outputs while minimizing on inputs. The Linear Programming technique enabled municipal management to identify local priorities rather than the goals imposed by pre-defined parameters. In the final analysis, linear programming was used to identify gaps that must be addressed by city managers to enhance actions taken. It also enabled to observe each municipal performance and compare results among similar municipalities.

Oral health is being free from mouth and facial pain, oral and throat cancer, oral infection and sores, periodontal disease, tooth decay, tooth loss and other diseases and disorders that limit an individual's capacity in biting chewing smiling, speaking and psychological wellbeing (Wikipedia, the free encyclopaedia). It is therefore a complex task for municipalities to provide Oral Heath in Primary Care centres, especially with over 50,000 habitants. However, with the application of linear programming, this is made easy and manageable.

\subsection{Application of Linear Programming in Mega Health Facilities}

Mason [14], looks at a Mega health facility in southern Carolina that maintains inpatient and outpatient services for the most acute cases of mental illnesses. It trains approximately 1,500 medical professionals per day, including more than 860 medical residents in nearly all medical specialties. It also trains 160 students for nursing and other health professions such as pharmacists, midwives, occupational, speech and respiratory therapists, dieticians, podiatrists, and laboratory and radiology technicians. The facility needed to maximize on the Outpatient building utilization and capacity across the network, maintain a very large number of specialty and sub-specialty outpatient services designed to meet community needs and meet complex scheduling requirements, both clinically and operationally, due to teaching requirements. The complexity and broad scope of this project required highly analytical expertise in service allocation methodologies and information technology.

The facility had to maintain visits of over 500,000 annually and accommodate Infusion Therapy Services for 22 patients in one location for adults, and 54 Infusion patients in another location for children. This Health Facility therefore needed to strategically enhance its ability to meet the community's needs while minimizing space requirements and optimizing space utilization. It thus sought the best operating model given the building constraints, while accommodating current service volumes and minimizing the move of services to the Community Health Centres. Linear programming was the tool that was used for solving these optimization problems.

Peterson and CoUege [15], also look at a model for locating public mental health outpatient facilities in a society that was opposed to having such a facility. The facilities must incorporate accessibility factors within budgetary constraints and include an opposition factor to spread risk, both real and perceived, in an equitable fashion. The size of the facilities must be small enough to effectively minimize opposition to their construction, yet large enough to allow economics of scale to operate. To achieve all these, a linear programming model with a threepart composite objective function was used.

\subsection{Linear Programming Applied to Healthcare Problems}

Moreira [16] presents a mathematical modelling technique by means of linear programming as an efficient tool to solve problems related to optimization in healthcare. These include; formulation of a balanced diet at a minimum cost and optimal allocation of resources for a set of medical interventions that comply with cost and medical visit restrictions. To illustrate this, an application of linear programming in diet formulation, assumed that a diet is restricted to skimmed milk and a salad using well-known ingredients. With all the restrictions in place, the optimal balanced diet was that which comprised of 1.4 glasses of skimmed milk per day with 100 $\mathrm{g}$ of salad per day, at a total minimum cost of $\mathrm{R} \$$ 2.55 per day. It is therefore observed that, in a 
world with increasingly scarce resources and every day more competitive, linear programming could be used to arrive at optimized solutions for healthcare problems.

Elsewhere in the Netherlands, Dooren et al. [17] try to find diets with low price and low climate impact that fulfil all nutritional requirements. They use optimization by linear programming with a program that constrains 33 nutrients to fulfil Dutch dietary requirements. The upper boundary was climate impact through greenhouse gas emissions that was set to $1.6 \mathrm{~kg}$ carbon dioxide equivalents per day. The lower boundary was the cost, set on $€ 2.50$ as a constraint. The objective function of the optimization maximized the most consumed food products for male and female adults separately. A diet of 63 popular and low priced basic products was found to deliver all required nutrients at an adequate level for both male and female adults. They therefore recommend linear programming as a promising tool to combine health and sustainability on both societal and individual levels. Thus the reason why linear programming should be taught to all learners at least up to secondary school level.

\subsection{Application of Linear Programming at Home Healthcare}

Home health care is a growing medical service. It includes medical, paramedical and social services delivered to patients at their own homes. The main benefits of home health care are the significant decrease in the hospitalization and the cost reduction in the entire health system. However, this service is not an easy task because it combines the vehicle routing problem and the nurse assignment problem. Thus a linear integer scheduling model was developed to provide staff short term planning in home care. In particular, the model deals with the problem of deciding; which patients should be assigned to each nurse and, when to execute the service during the planning horizon, in order to satisfy the time windows constraints for each patient [5].

Zon and Kommer [18] also present a deterministic allocation model in which a patient's health-state changes due to health-care interventions. This change in a patient's health-state has a direct effect on the patient's expected future need for health-care. Hence, current allocation decisions determine to some extent the set of possible allocation decisions in the future. In order to take this into account they formulated a dynamic linear programming version of a patient-flow system. This enabled them to describe the effects of using different objective functions on the optimum level and composition of the provision of health services within given resource constraints. The linear programming approach enables the quantification of the health effects and therefore the desirability of the re-allocation of health-care resources.

Furthermore, Kun [19] looks at Linear Programming and the Most Affordable Healthy Diet. Most people want to minimize the amount of money spent on food. At the same time, one needs to maintain a certain level of nutrition. For males ages 19-30, the United States National Institute for Health recommends 3.7 litres of water per day, 1,000 milligrams of calcium per day, 90 milligrams of vitamin $\mathrm{C}$ per day, etc. One can set up this nutrition problem mathematically, and by using linear programming identify cheapest healthy diet. Meanwhile, Carvalho [20] explains the possibility of using linear programming to formulate a nutritious, minimum-cost porridge mix for children aged 1 to 2 years. In their study, they found a nutritious porridge fulfilling the consistency constraints. They therefore concluded that the optimizations were successful in fulfilling all constraints and provided a feasible porridge. This shows that linear programming methodology provides a systematic tool for designing nutritious foods.

\subsection{Some Questions on Linear Programming and Health}

On the Math Forum @ Drexel, Anderson asks the following question, 'A nutrition centre sells health food to mountain climbing teams. The Trailblazer mix package contains one pound of corn cereal mixed with four pounds of wheat cereal and sells for $\$ 9.75$. The Frontier mix package contains two pounds of corn cereal mixed with three pounds of wheat cereal and sells for $\$ 9.50$. The centre has 60 pounds of corn cereal and 120 pounds of wheat cereal available. How many packages of each mix should the centre sell to maximize its income? Find the inequalities and vertices'. Anderson further states; 'I have spent a lot of time on this, asked three adults for help, referred to my book, and still can't solve this problem. This has been very frustrating to everyone who has looked at it. Can you help'? 
This question, and especially the last statement, indicates that many people have difficulties in solving linear programming problems, leave alone applying linear programming knowledge and skills to daily life activities. Thus the reason why linear programming should be taught to learners at all levels, not just in Kenya but beyond boarders.

Doctor Daniel answers Anderson by explaining that, the problem asked is a linear programming problem. This is not a programming in the sense of C or Java. Rather, it is to find a program, which it values for a bunch of variables, where the values from the program maximize the income of the centre. The "linear" in the description of the problem is because the amount of money the store gets from selling the product is a linear function; if it sells 2 units of Trailblazer, it gets twice as much money than if it sells 1 unit. This is a good example of applying linear programming to maximize on profits while minimizing on costs.

Perez [21] also looks at how Restaurants use linear programming for menu planning. It uses basic algebra to optimize meal production and thereby increase restaurant profits. Linear algebra reflects a direct relationship between an increase or decrease in food resources, and an increase or decrease in meal production. For example, if the kitchen has only half its needed supply of cream base, then it can only prepare half its normal amount of cream soups. Additionally, management can determine the cost of preparing different menu items to decide how many of each menu item to prepare for optimal profit.

The question is 'How Do Restaurants Use Linear Programming for Menu Planning?' to answer this question a number of steps are followed. First, choose the decision variables that apply. In this example, a restaurant needs to produce 250 of its dinner specials per day, one with meat and the other vegetarian. The decision variables are the number of meals and the different menu names. Therefore, choose the objective for the restaurant. Normally, the objective is to determine how many of each menu item to prepare that meets the required number of meals yet stays within budget, so this is the objective for the example shown. However, the objective will be the quantity of physical supplies on hand. If there is a shortage of a particular ingredient that several menu items use, such as tomato sauce, then management can determine how to get the largest number of meals with the quantity of tomato sauce on hand. Choose the constraints on menu production, which is the day's monetary budget to produce a specified number of meals. For example, a restaurant has a $\$ 1,000$ budget for that day's two dinner specials, and it must prepare 250 meals that cost different amounts to prepare. It cannot spend more than $\$ 1,000$ and still earn a profit. Choose the two dinner specials, such as porterhouse steak and spinach lasagna. For this example, the porterhouse steak costs $\$ 7$ to prepare and the lasagna dinner costs $\$ 3$. With all objective functions identified, Perez advices how to calculate such that the restaurant is able to meet customer demands, yet make a profit.

\subsection{Use of Linear Programming in Strategic Health Human Resource Planning}

There are many cases in human health, where linear programming has to be applied. For example, Romeijn [22] considered the problem of radiation therapy treatment planning for cancer patients. During radiation therapy, beams of radiation pass through a patient, killing both cancerous and normal cells. Thus, the radiation therapy must be carefully planned so that a clinically prescribed dose is delivered to targets containing cancerous cells, while nearby organs and tissues are spared. Currently, a technique called intensity-modulated radiation therapy (IMRT) is considered to be the most effective radiation therapy for many forms of cancer. In IMRT, the patient is irradiated from several beams, each of which is decomposed into hundreds of small beam-lets, the intensities of which can be controlled individually. In their paper, Lavieri et al. [23] considered the problem of designing a treatment plan for IMRT when the orientations of the beams are given. They proposed a new model that had the potential to achieve most of the goals with respect to the quality of a treatment plan that had been considered to date. In fact, they did this while retaining linearity of the optimization problem, which substantially improves the tractability of the optimization problem. Thus linear programming is applied to ensure that only cancerous cells are destroyed, while normal cells are spared.

Apart from the treatment, care needs to be taken to ensure that every patient is under the care of a qualified nurse. It is for this reason that Satheeshkumar et al. [7] looked at Linear 
Programming Applied to Nurses Shifting Problems. In any hospital, the primary mission is to ensure continuous ward care service with appropriate number of nursing staffs and the right mix of nursing skills. The planning and scheduling is done to avoid additional nonessential cost to the hospital. Nurses' preferences are taken into considerations such as the number of night shift and consecutive rest days. The aim was to present a mathematical modelling technique by means of linear programming as an efficient tool to solve problems related to optimization in healthcare. Hospitals must be staffed 24 hours a day by a limited number of nurses. In their paper, Satheeshkumar et al. [7] illustrate how linear programming solves the nurses scheduling problems. The paper illustrates how linear programming was effectively used in Nurses scheduling at a multi-specialty Hospital in Coimbatore.

Lavieri et al. [23], also look at the use of linear programming in strategic health human resource planning. They focus on a multiperiod linear programming approach that compares all feasible human resource strategies to identify education, recruitment, and promotion plans that achieve a supply-demand balance at the least cost to the system. The approach applies to a wide range of healthcare provider groups contingent on data availability. Potential sources include regulatory, educational, employer, government and administrative databases, and research publications. Its ease of use and strong mathematical foundation make this model ideal for analysis and assessments of sensitivity of decisions to assumptions and data accuracy.

\section{CONCLUSION AND RECOMMENDA TION}

From the foregoing, linear programming, a topic in the Kenyan mathematics curriculum is key in maximizing on profits, while minimizing costs in health care. Application of linear programming knowledge and skills, therefore goes a long way in the improvement of health care. It is therefore recommended that linear programming be taught to all learners, at both primary and secondary school levels in Kenya and beyond. It is also recommended that, as many health facilities as possible should identify linear programming models that will help in management of resources, management of manpower, and maximize in profits while minimizing on costs. This will go a long way into improving and maintaining a healthy society.

\section{COMPETING INTERESTS}

Author has declared that no competing interests exist.

\section{REFERENCES}

1. Cockcroft WH. Mathematics counts: A report of the committee into the teaching of mathematics in schools. London: Her majesty's stationary office; 1982.

2. Kenya Institute of Education, (KIE). The secondary school syllabus: Government Printers, Nairobi. 2002;2.

3. Mulholland MW, Abrahamse $P$, Bahl V. Linear programming to optimize performance in a department of surgery. $J$ Am Coll Surg. 2005;200(6):861-8.

4. Alan Lyles. Linear programming explained. Copyright (c) 2005 John Wiley \& Sons, Ltd.; 2005.

5. Sarra Trabelsi, Rim Larbi, Atidel Hadj Alouane. Linear integer programming for the home health care problem. Business Process Management Workshops. Volume 100 of the series Lecture Notes in Business Information Processing. 2012; 143-151.

6. Frederico Rafael Moreira. Linear programming applied to healthcare problems. Clinical Research Center of Hospital Israelita Albert Einstein. Einstein. 2003;1:105-9.

7. Satheeshkumar S, Nareshkumar S, Kumaraghuru. Linear programming applied to nurses shifting problems. International Journal of Science and Research (IJSR). 2014;3(3).

Available:www.ijsr.net ISSN (Online):2319-7064

8. Shikuku BN. Effect of Syllabus coverage on student performance in Mathematics: A case of Kakamega South district, Kenya. Unpublished Thesis, Masinde Muliro University of Science and Technology; 2009.

9. John Aluko Orodho. Elements of education and social science research methods. Kenezja Publishers; 2005.

10. Alan Bryman. Social research methods. $4^{\text {th }}$ Edition: Oxford Academia.edu; 2004.

11. Sotirios Sarantakos. Social research. Palgrave Macmillan; 2005. 
12. Alexandr Parlesak, Inge Tetens, Jørgen Dejgård Jensen, Sinne Smed, Mojca Gabrijelčič Blenkuš, Mike Rayner, Nicole Darmon, Aileen Robertson. Use of linear programming to develop cost-minimized nutritionally adequate health promoting food baskets; 2016.

Available:https://doi.org/10.1371/journal.po ne.0163411

13. Claudia Flemming Colussi, Maria Cristina Marino Calvo, Sergio Fernando Torres de Freitas. Linear programming to evaluate performance of oral health in primary care. Print version Einstein (São aulo). Health Economics and Management. 2013;11(1). São Paulo.

ISSN 1679-4508

Available:http://dx.doi.org/10.1590/S167945082013000100017

14. Mason SJ, Hill RR, Mönch L, Rose O, Jefferson $T$, Fowler JW. A linear programming model that maintains inpatient and outpatient services for the most acute cases of mental illnesses in a hospital that trains approximately 1,500 medical professionals per day. Proceedings of the 2008 Winter Simulation Conference; 2008.

15. Phyillis Peterson A, Hunter CoUege. Application of linear programing to locating mental health outpatient facilities. Department of Geology and Geography, C.U.N.Y. New York. New York 10021; 1991.

16. Frederico Rafael Moreira. Linear programing applied to health care problems. Hospital Israelita Albert Einstein Av. 2003;627-701.

17. Corné van Dooren, Marcelo Tyszler, Gerard Kramer FH, Harry Aiking. Article combining low price, low climate impact and high nutritional value in one shopping basket through diet optimization by linear programming. Sustainability. 2015;7: 12837-12855.

DOI: $10.3390 /$ su70912837

ISSN 2071-1050

Available:www.mdpi.com/journal/sustainab ility

18. Van Zon AH, Kommer GJ. Patient flows and optimal health-care resource allocation: A dynamic linear programming approach. Health Care Management Science. 1999;2(2):87-96.

19. Jeremy Kun. Linear programming and the most affordable healthy diet.

Available: http://wwwKun.com/2014/06/02 (Accessed 20/03/2017)

20. Irene Stuart Torrié De Carvalho, Yvonne Granfeldt, Petr Dejmek, Andreas Håkansson. Using linear programming to formulate a nutritious, minimum-cost porridge mix for children aged 1 to 2 years. From Diets to Foods: First Published; 2015.

21. Diane Perez, Demand Media. How do restaurants use linear programming for menu planning? Ads by Google Free optimization tool.

Available: www.jmodelica.org (Accessed 20/03/2017)

22. Edwin Romeijn $\mathrm{H}$, Ravindra Ahuja $\mathrm{K}$, James Dempsey F, Arvind Kumar. A new linear programming approach to radiation therapy treatment planning problems. Home Operations Research. 2005;54(2): 201-216.

Available:http://dx.doi.org/10.1287/opre.10 $\underline{50.0261}$

23. Mariel Lavieri S, Sandra Regan, Martin Puterman L, Pamela Ratner A. Introduction to the use of linear programming in strategic health human resource planning. Copyright (c) 2010 John Wiley \& Sons, Inc; 2015.

(0) 2017 Shikuku; This is an Open Access article distributed under the terms of the Creative Commons Attribution License (http://creativecommons.org/licenses/by/4.0), which permits unrestricted use, distribution, and reproduction in any medium, provided the original work is properly cited. http://sciencedomain.org/review-history/19041 